\title{
Discrete Element Simulation of Roadway Stability in an Efflorescent Oxidation Zone
}

\author{
Qifeng Zhao, ${ }^{1,2}$ Nong Zhang $\left(\mathbb{D},{ }^{1}\right.$ Rui Peng, ${ }^{2}$ Guichen Ll $\mathbb{D}^{1},{ }^{1}$ Changliang Han, ${ }^{1}$ and Yu Guo \\ ${ }^{1}$ Key Laboratory of Deep Coal Resource Mining, Ministry of Education of China, School of Mines, \\ China University of Mining and Technology, Xuzhou, Jiangsu 221116, China \\ ${ }^{2}$ School of Safety Engineering, North China Institute of Science and Technology, Sanhe, Hebei 065201, China
}

Correspondence should be addressed to Nong Zhang; zhangnong@cumt.edu.cn

Received 10 November 2017; Accepted 12 March 2018; Published 2 May 2018

Academic Editor: Rihong Cao

Copyright (c) 2018 Qifeng Zhao et al. This is an open access article distributed under the Creative Commons Attribution License, which permits unrestricted use, distribution, and reproduction in any medium, provided the original work is properly cited.

Due to crustal movement, coal-bearing strata weather and oxidise when exposed to the atmosphere and water. The unique geological characteristics of the rock in efflorescent oxidation zones lead to variations in lithology, weak rock, and large failures due to deformation. This paper analyses the variable physical mechanics and microstructural characteristics of efflorescentoxidised coal rock using the UDEC numerical simulation software. The software is used to study the gradual development, dynamic expansion, and deformation of cracks in the material surrounding efflorescent rock tunnels. These numerical simulations reveal information concerning the evolution of surrounding rock attenuation, strength, and deformation. The destruction and causes of roadway failure were also analysed, and optimisation measures were proposed. The results from this study have applications for other research concerning roadway failure, deformation mechanisms, and the addition of appropriate supports.

\section{Introduction}

With the depletion of coal resources in eastern China, mine exploitation has gradually shifted to Shanxi, Inner Mongolia, and Xinjiang. The middle and western parts of China have abundant coal resources including the Shenfu Dongsheng, Datong, and Qinshui coalfields, which have shallow, high-quality coal that have become important coal resources for China. However, mines in these areas primarily encompass zones of efflorescent oxidation. Following the formation of coal-bearing systems, deformation of efflorescent oxidation formations occurs due to tectonic activity. The formation suffers from erosion and denudation by surface processes, and oxidation occurs through interactions with the atmosphere and water. Efflorescent oxidation dictates the structure of the coal and rock mass, and its compressive strength is $10 \%-15 \%$ of the similar, nonweathered rock $[1,2]$. The oxidised rock mass has strong hydrophobicity and is susceptible to water erosion $[3,4]$. Due to the loose surrounding rock structure, low strength, and poor cementation, roadway excavation in efflorescent-oxidised rock mass results in significantly decreased roadway and support capacities. The initial rapid deformation in these rock layers is of high magnitude. Thus, the soft rock, coupled with mining impacts, results in the failure of roadway supports and the instability of load bearing structures, which frequently collapse [5]. The stability of the roadway and surrounding rock with tunnel construction safety results in significant security risks.

In order to effectively control roadway and surrounding rock stability, researchers have investigated the mechanisms of deformation and failure in efflorescent oxidation zones. Meng et al. [6] use a loose circle test, in situ stress measurements, rock mechanical property tests, mineral composition analysis, rock deformation, and stress monitoring and observations of the supporting structure to study the deformation mechanisms of a roadway built in argillaceous soft rock in the Dongsheng coal mine of the Shenfu coalfield. This study proposes an optimal layout and support design, thus providing reference and context for this study. This study also uses the surrounding rock thickness and the loose circle test to quantitatively determine the soft rock 
characteristics and to analyse the nonlinear deformation and failure mechanisms. He et al. [7] studied the molecular failure of the rock mass surrounding a soft rock roadway, the composite structural plane rock mass failure mechanism, and the disturbance due to excavation. This paper proposes using a combination of coupling and high prestress bolt supports to stabilise the soft rock system. Wang et al. [8] puts forward a new deep-shallow coupling using a fullface bolt grouting support technology system with a "hollow grouting anchor cable and high strength grouting bolt" core. The mutual coupling of the surface and depth components forms the supporting body. Kang et al. [9] proposes a support system with high prestress and strong bolts for soft rock roadways. W. Lawrence designed the gateroad roof support model and applied it to coal roadways. Shen [10] and Gao [11] used numerical simulation software to analyse the influence of the fracture field distribution in tunnels built under different geological conditions and proposed corresponding support technology. In areas of efflorescent oxidation, it is critical to understand the fracture mode of the surrounding rock and the appropriate methods of support.

Due to the complexity of weakly oxidised rock, further investigation is required to elucidate the failure mechanisms and to develop appropriate supporting technology for these areas. Along large mining roadways in efflorescent oxidisation zones, loose and broken rock mass is visible from large road cuts, and stabilising the roadway is difficult. Research concerning rock failure and supporting technology in efflorescent oxidation zones is limited, and findings are preliminary.

The deformation and destruction of surrounding rock in efflorescent rock mass is due to the heterogeneous, weakly cemented microfracture structure. Deformation in efflorescent rock mass is a continuous accumulation process resulting in the evolution of fractures. Traditional continuum mechanics and finite element numerical simulation software assume a small-magnitude deformation, and it is difficult to directly simulate the progressive failure of jointed rock masses. Furthermore, the results are not consistent with the fact that the rocks surrounding the efflorescent tunnel are in a state of rupture. The discrete element (DEM) simulation software is used to study the evolution of deformation and failure in weakly oxidised coal and rock mass and offers many advantages compared to other methods [12]. With respect to the finite difference method and finite element software, DEM simulation can more effectively characterise the coal rock mass and provide a nongeometric simulation of continuously jointed features, including block sliding, rotating, and caving. As many of these features are present in the study area, the discrete element simulation software was used to simulate the deformation and fracture of the rock surrounding the efflorescent layer.

In the fields of efflorescent-oxidised rock mass fissure development and roadway collapse mechanisms, many scholars focus on single rock mechanics experiments or development expansion until the destabilisation. Efflorescent oxidation seriously damaged the number 39107 auxiliary transport roadway of Pingshuo coal mine. Through numerical software analysis calibrated with efflorescent oxidation parameters (using FISH), the block unit in the UDEC software improved the Voronoi block model into a random triangle model. This block can be used to simulate the deformation and the development of cracks in the surrounding rock. This paper analyses the deformation and failure mechanisms in the weakly oxidised roadway rock and proposes a suitable stability control for use in roadway development.

\section{Geological Setting}

The coal mining area in northern Shanxi province is an important coal resource. The area is significant because of the coal formation conditions, shallow coal seam area, and the improved upper limit of mining. Poor cementation and oxidation cause large deformation of rock surrounding in roadway excavations, resulting in structural instability and caving. There have been collapses of rock with varying degrees of efflorescent oxidation. In the Pingshuo mine, three efflorescent oxidation zones in roadway excavations posed a significant threat to mine safety. Pingshuo underground coal mine is located in Shanxi Province, Pinglu District, as shown in Figure 1. Representative physiognomy of the mining areas is shown in Figure 2. At present, there is a lack of research on the large deformation instability mechanisms of the rock surrounding efflorescent roadways.

In an area of widely distributed loess with little vegetation cover, landforms are susceptible to erosion and form beam wall and hilly loess plateau landforms. During the Middle Ordovician, the North China Platform suffered longterm weathering and denudation due to fault activity. These effects included coal seam scouring, oxidation of varying degrees, and local erosion of the surrounding rock units, leaving overlying bedrock thin or missing and thus a threat to mine safety.

The number 39107 working face is located in the northern part of the east mining area, as shown in Figure 1. The thickness of the number 9 coal deposit ranges from 7 to $11 \mathrm{~m}$, and the coal seam sits at an angle of $2^{\circ}$. This dip angle anomaly in the coal seam is the result of efflorescent oxidation and nearby faults. Hydraulic fracturing was used to test the in situ stress of the large efflorescent roadway near the number 39107 working face. Measured values of $\sigma_{h \text {-max }}, \sigma_{h \text {-min }}$, and $\sigma_{v}$ were $7.2 \mathrm{MPa}, 4.3 \mathrm{MPa}$, and $5.6 \mathrm{MPa}$, respectively.

The azimuth angle of the maximum horizontal principal stress was $67^{\circ}$, the azimuth angle of the number 39107 auxiliary roadway was approximately $5^{\circ}$, and the angle between the directions of the maximum horizontal principal stress was approximately $62^{\circ}$. As both of these angles are vertical, the roadway is affected by horizontal stress. The number 39107 auxiliary roadway is located within the \#9 coal seam, which is situated in the middle of a sandstone unit with an average thickness of $2.3 \mathrm{~m}$. This sandstone unit sits below a mudstone layer with an average thickness of $2.7 \mathrm{~m}$. A sandy mudstone layer with an the average thickness is $1.48 \mathrm{~m}$ sits directly above the coal seam, and the basic roof is a coarse sandstone with an average thickness of $10.6 \mathrm{~m}$. The number 39107 auxiliary roadway was built along the number 9 coal seam, which encompasses a large shallow efflorescent 

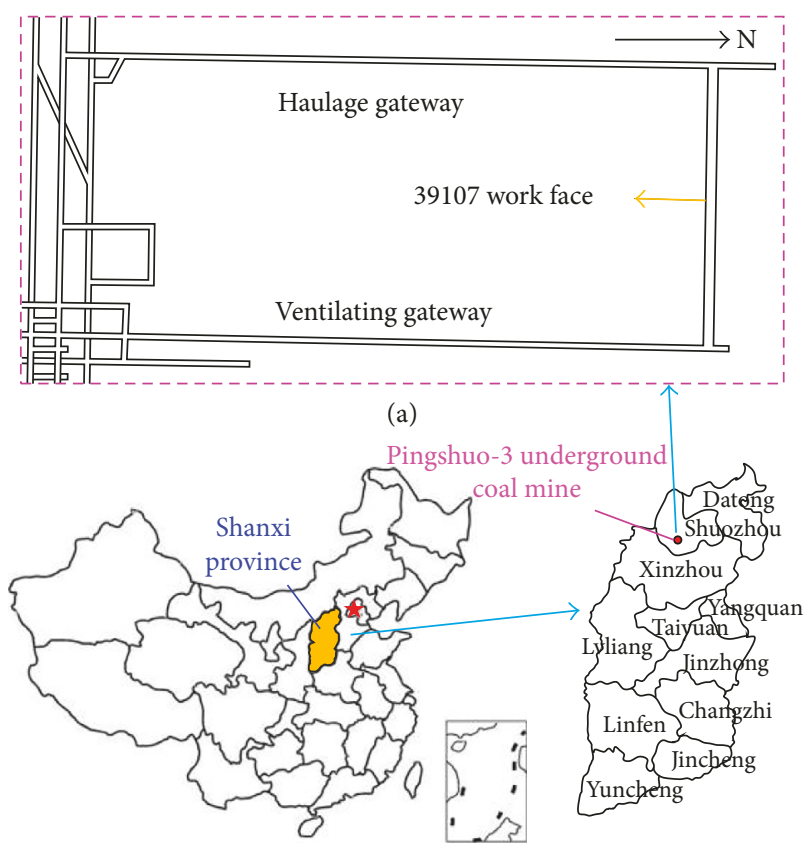

(b)

Figure 1: (a) Plan view of the roadway and panel of the study site and (b) location of Pingshuo-3 underground coal mine.

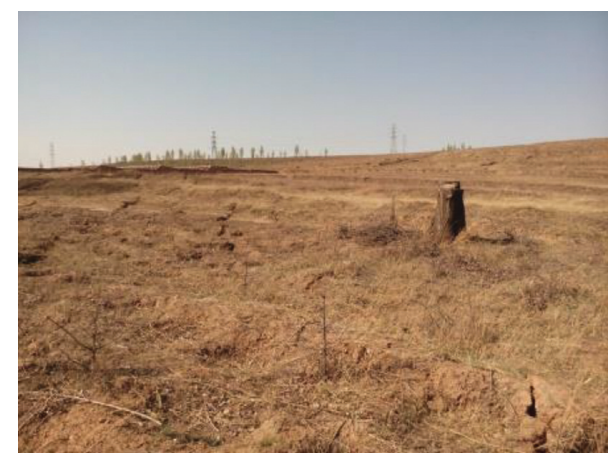

FIgURE 2: Representative mining area physiognomy.

oxidation zone and is $1230 \mathrm{~m}$ long, $5.0 \mathrm{~m}$ wide, and $3.5 \mathrm{~m}$ high.

The roadway was initially designed using an anchor net spray, anchor cable, and steel strip roof supports $(6 \times 22 \times 2400 \mathrm{~mm}$ bolts with $900 \times 900 \mathrm{~mm}$ row spacing and two sets of six rows of $7 \times 18 \times 1700 \mathrm{~mm}$ round bar anchors, with a row spacing of $800 \mathrm{~mm}$ ). The cable was constructed of $17.8 \times 7300 \mathrm{~mm}$ steel strand, rectangular along the direction of the roadway with a row spacing of $1800 \times 2700 \mathrm{~mm}$. Due to the shallow buried coal seam, the roof lithology has been affected by weathering and other geological processes, and thus, the geological conditions for engineering have changed over time.

During roadway excavation in the efflorescent oxidation zone, cracks developed, the roof collapsed, and the bolts could not be used. This roof failure, which resulted in a mixture of yellow sandstone and mudstone deposited on the roadway, is still challenging to control. Material in the roadway such as these significantly affects the safety and efficiency of excavation and construction. A synthesis column map of the number 39107 roadway strata is shown in Figure 3. The lithologic characteristics of the efflorescentoxidised rock mass are shown in Table 1.

\section{Variation in the Efflorescent Oxidation Zone}

3.1. Range of Efflorescent Oxidation and the Roof Rock Integrity. To obtain a reasonable estimate of the range of efflorescent oxidation at the study site, an analysis of rock integrity and the degree of rock oxidation along the number 39107 auxiliary roadway was compared with data from three wells from the drilling exploration area at the coal mine. Results are summarised below.

(1) The strata exposed by the existing boreholes in the three mine wells are shown in Table 2 and Figure 4. At depth, efflorescent oxidation of the \#9 coal seam is significant, and the degree of oxidation diminishes toward the surface. The number 39107 fully mechanised coal caving face outside the mining area shows significant efflorescent oxidation, while the working face shows only local invasions of oxidation. The number 39107 auxiliary roadway is only partially in the oxidation zone and shows efflorescent oxidation from the QF9 control point to the open cut at $525 \mathrm{~m}$. This area is the focus of this study.

(2) The roof of the roadway in the efflorescent oxidation zone is shown in Figure 5. Weathering has removed the coal layer overlying the roadway, and the mudstone unit on the surface of the roadway has weathered to silt and clay. Drilling is challenging as the coal and mudstone units overlying the roadway are significantly oxidised, and only a few small pieces of the broken rock blocks from the column are removable. The RQD value is zero. It was originally the basic roof of medium sandstone, moderate efflorescent-oxidised weak weathering of yellow sandstone, and yellow mudstone result in an RQD value of $20.5 \%$, but still has a certain thickness as the roof is not completely weathered away. Thus, it is very important to stabilise the rock surrounding the number 39107 roadway.

\subsection{Physical and Mechanical Characteristics of the Coal and Rock Mass}

(1) Water content of the slate layer in the upper efflorescent oxidation zone reaches $32.27 \%$, indicating significant efflorescent oxidisation.

(2) The void ratio of the upper coal and roof layers is between 0.681 and 0.984 , indicating oxidisation to compressed soil.

(3) The permeability coefficient for the upper coal and roof rock samples is $2.08 \times 10^{-5} \mathrm{~cm} / \mathrm{s}$, signifying weakly permeable rock mass. 


\begin{tabular}{|c|c|c|c|}
\hline Remark & Lithology & $\begin{array}{l}\text { Thick } \\
(\mathrm{m})\end{array}$ & $\begin{array}{l}\text { Coal-rock } \\
\text { columnar }\end{array}$ \\
\hline & Mudstone \# 1 & 10.2 & \\
\hline Main roof & Gritstone \#1 & 9.6 & \\
\hline \multirow{2}{*}{$\underset{\text { roof }}{\text { Immediate }}$} & Mudstone \#2 & 1.5 & \\
\hline & Number 9 coal & 7.3 & \\
\hline $\begin{array}{l}\text { Immediate } \\
\text { floor }\end{array}$ & Mudstone \#3 & 2.7 & \\
\hline \multirow[t]{4}{*}{ Main floor } & $\begin{array}{l}\text { Medium-fine } \\
\text { sand tone }\end{array}$ & 2.3 & \\
\hline & Gritstone \#2 & 6 & \\
\hline & Musdtone \#4 & 2 & \\
\hline & Number 11 coal & 5 & \\
\hline
\end{tabular}

(a)

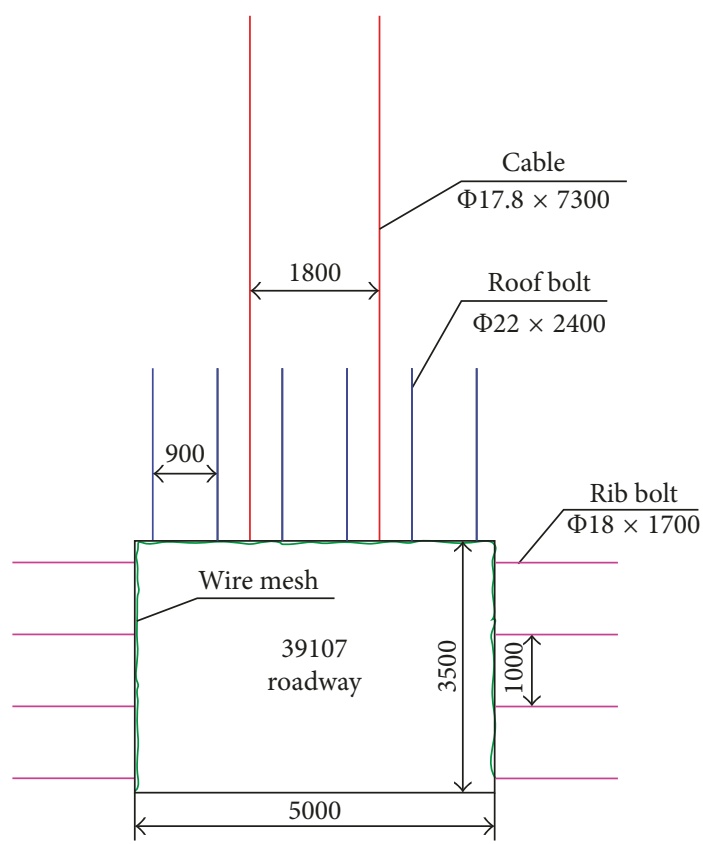

(b)

Figure 3: (a) Synthesis column map of the number 39107 auxiliary roadway strata and (b) corresponding support scheme.

TABle 1: Coal seam roof and floor lithology and the characteristics of efflorescent-oxidised rock mass.

\begin{tabular}{|c|c|c|c|c|c|}
\hline Classification & Lithology & $\begin{array}{l}\text { Thickness } \\
(\mathrm{m})\end{array}$ & Characteristics of efflorescent-oxidised rock mass & RQD (\%) & $\begin{array}{c}\text { Drill core } \\
\text { photographs }\end{array}$ \\
\hline Main roof & Gritstone & 10.6 & $\begin{array}{c}\text { Faint yellow colour, weak lustre, fractured, loose } \\
\text { structure }\end{array}$ & $45.4-56.7$ & \\
\hline $\begin{array}{l}\text { Immediate } \\
\text { roof }\end{array}$ & Mudstone & 1.48 & $\begin{array}{l}\text { Weak lustre, water-swelling clays, fractured, high } \\
\text { level of efflorescent oxidation in clay }\end{array}$ & $5.2-18.5$ & \\
\hline Number 9 coal & Coal & 9 & $\begin{array}{l}\text { Soil lustre, sepia, water-swelling clay, high level of } \\
\text { efflorescent oxidisation in clay }\end{array}$ & 0 & \\
\hline $\begin{array}{l}\text { Immediate } \\
\text { floor }\end{array}$ & $\begin{array}{l}\text { Medium } \\
\text { sandstone }\end{array}$ & 2.3 & $\begin{array}{l}\text { Faint yellow colour, weak lustre, fractured, } \\
\text { unconsolidated structure }\end{array}$ & $45.4-56.7$ & \\
\hline Main floor & Mudstone & 2.7 & $\begin{array}{c}\text { Sepia, soil lustre, fractured, unconsolidated } \\
\text { structure }\end{array}$ & $5.2-18.5$ & \\
\hline
\end{tabular}

TABle 2: Borehole parameters and the efflorescent oxidation zone thickness on the number 39107 working face.

\begin{tabular}{|c|c|c|c|c|c|c|c|}
\hline Identifier & Location & $\begin{array}{l}\text { Ground } \\
\text { elevation } \\
\text { (m) }\end{array}$ & $\begin{array}{l}\text { Thickness } \\
\text { of erosion } \\
\text { (m) }\end{array}$ & $\begin{array}{l}\text { Thickness } \\
\text { of bedrock } \\
(\mathrm{m})\end{array}$ & $\begin{array}{c}\text { Interval of } \\
\text { efflorescent } \\
\text { oxidisation }(\mathrm{m})\end{array}$ & $\begin{array}{l}\text { Vertical distance } \\
\text { between the ground and } \\
\text { the number } 9 \text { coal seam } \\
(\mathrm{m})\end{array}$ & Notes \\
\hline OX-104 & \multirow{2}{*}{$\begin{array}{l}\text { Outside of } \\
\text { the mining } \\
\text { area }\end{array}$} & 1437.58 & 27.00 & 111.12 & $134-140$ & 138.12 & \multirow{4}{*}{$\begin{array}{l}\text { The number } 9 \text { coal seam } \\
\text { and overlying strata are } \\
\text { all in the efflorescent } \\
\text { oxidisation zone } \\
\text { The local area surrounding } \\
\text { the number } 39107 \text { roadway } \\
\text { is in the efflorescent } \\
\text { oxidisation zone }\end{array}$} \\
\hline OX-105 & & 1415.92 & 18.89 & 113.81 & $128-138$ & 132.70 & \\
\hline $110-130$ & & 1392.98 & 27.00 & 98.53 & $86-93$ & 125.53 & \\
\hline W-3 & $\begin{array}{l}\text { Within the } \\
\text { mining area }\end{array}$ & 1379.73 & 26.10 & 133.9 & $132-140$ & 160.0 & \\
\hline
\end{tabular}




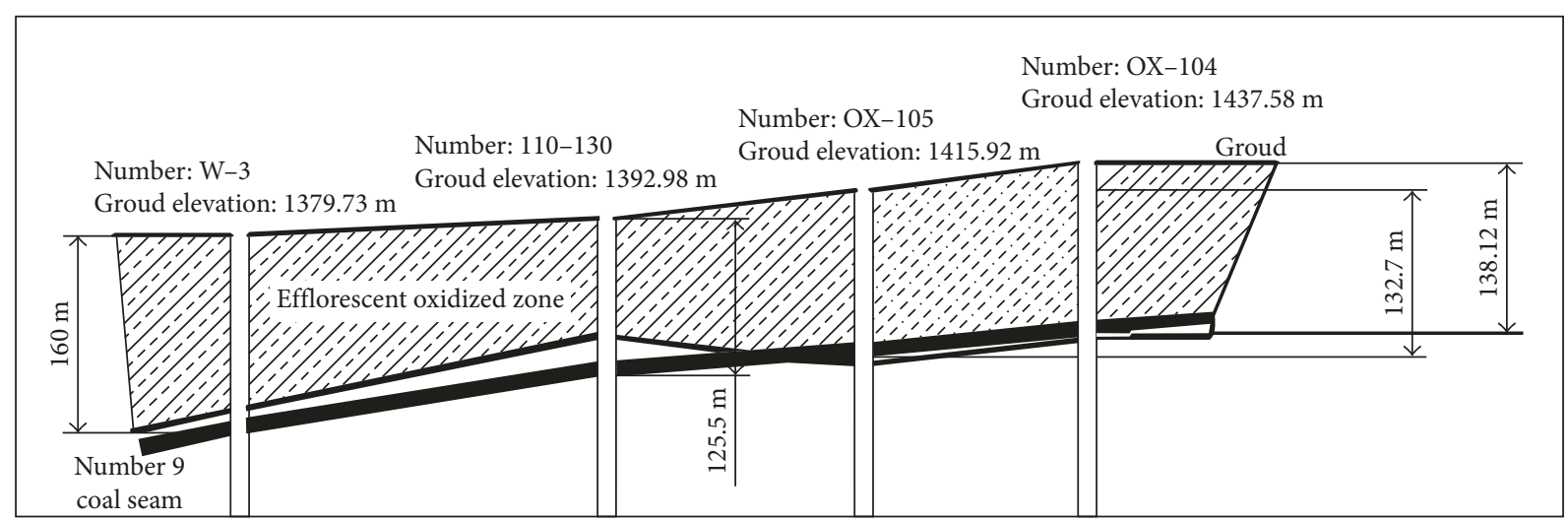

FIGURE 4: Borehole profiles.

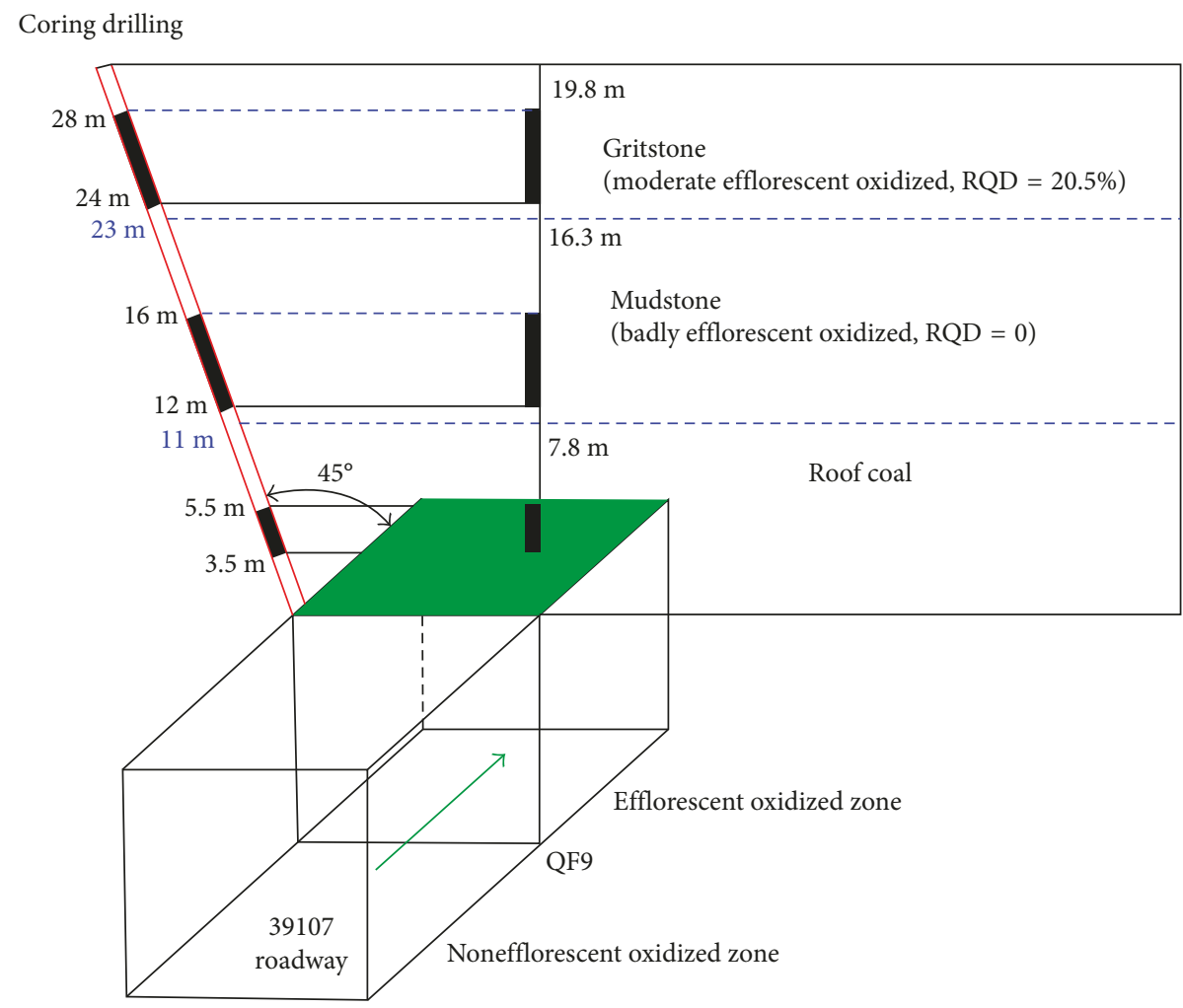

Figure 5: Core drilling in the number 39107 roadway roof.

The physical and mechanical parameters of the coal seam and of the slate layer along the number 39107 roadway were obtained by in situ coring and rock mechanic tests. The results are shown in Table 3 .

\subsection{Influence of Efflorescent Oxidation on Surrounding Rock} Stability. The results shown above underscore the influence of the depositional environment and accumulation of weathering damage on the surrounding rock stability. Efflorescent oxidation along the number 39107 auxiliary transport roadway also influences the distribution of loose structures and fissures and contributes to the poor cementation, low strength, and poor stability characteristics of the surrounding rock. The significant weathering of the rock mass increases plasticity while, concurrently, decreasing the stability and bearing capacity. As a result, local roof failures are likely to occur.

\section{Discrete Element Simulation}

4.1. Discrete Element Method. The significant discontinuities (e.g., cracks, joints, bedding, and mineral composition differences) in the engineering rock mass limit the application of the continuous method to rock mechanic problems. The discrete element method (DEM) is a widely used 
TABle 3: Physical and mechanical parameters of rock strata.

\begin{tabular}{|c|c|c|c|c|c|c|}
\hline Lithologic unit & $\begin{array}{c}\text { Elastic modulus, } E_{\mathrm{r}} \\
(\mathrm{GPa})\end{array}$ & $\begin{array}{l}\text { Poisson's } \\
\text { ratio, } v\end{array}$ & $\begin{array}{l}\text { Density } \\
\left(\mathrm{kg} / \mathrm{m}^{3}\right)\end{array}$ & $\begin{array}{c}\text { Friction angle, } \\
\Phi\left({ }^{\circ}\right)\end{array}$ & $\begin{array}{l}\text { Cohesion, } C \\
(\mathrm{MPa})\end{array}$ & $\begin{array}{c}\text { Compressive strength, } \sigma_{\mathrm{c}} \\
(\mathrm{MPa})\end{array}$ \\
\hline Mudstone \#1 & 4.6 & 0.12 & 2370 & 39 & 5.4 & 15.7 \\
\hline Gritstone \#1 & 10.0 & 0.25 & 2652 & 45 & 7.4 & 38.1 \\
\hline Mudstone \#2 & 4.6 & 0.26 & 2346 & 38 & 4.7 & 19.1 \\
\hline Number 9 coal & 3.2 & 0.25 & 1498 & 35 & 2.7 & 11.7 \\
\hline Mudstone \#3 & 4.6 & 0.26 & 2346 & 38 & 4.7 & 19.1 \\
\hline $\begin{array}{l}\text { Medium-fine } \\
\text { sandstone }\end{array}$ & 13.0 & 0.21 & 2641 & 42 & 9.3 & 36.3 \\
\hline Gritstone \#2 & 9.0 & 0.29 & 2450 & 46 & 13.4 & 36.6 \\
\hline Mudstone \#4 & 4.6 & 0.26 & 2332 & 35 & 4.7 & 17.4 \\
\hline Number 11 coal & 3.2 & 0.25 & 1498 & 36 & 2.7 & 11.7 \\
\hline
\end{tabular}

noncontinuum method [13] and assumes that the research object is part of a series that includes complete rigidity, deformable block, or sphere behaviour. Defining the mechanical contact behaviour between a block and/or a sphere simulates the stress, movement, and deformation [14]. UDEC is a software program that solves two-dimensional rock mechanics problems using the DEM. UDEC describes the block and the contact components by continuous mechanical and contact relationships, respectively. The contact is the boundary of the continuum rock, considered a single continuum, and the contacts with other continuous blocks are processed as separate objects. Additionally, the block can have either deformation or rigid characteristics. In this paper, we divide the Voronoi random polygon blocks generated by UDEC into triangular blocks with a custom FISH function $[15,16]$. Dividing the blocks into triangles, as opposed to quadrilateral or polygonal blocks, is a more suitable representation of the rocks in this study.

UDEC software also provides several joint material models, such as the point-contact coulomb sliding model, surface-contact coulomb sliding model, and the continuous yield model. The surface-contact coulomb sliding model is most suitable for excavation simulations in underground rock mass. Generally, the joint opening, shear yield, and swelling effects can be discerned by simulating the contact behaviour of the joint surface with the spring slider. According to the stress-displacement relationship, the force is divided into normal and tangential stresses. Assuming a linear relationship between stress and displacement, controlled by the normal stiffness coefficient, $K_{n}, \Delta \sigma_{n}$ is the normal stress increment and $\Delta u_{\mathrm{n}}$ is the normal displacement increment:

$$
\Delta \sigma_{\mathrm{n}}=-K_{\mathrm{n}} \Delta u_{\mathrm{n}}
$$

In (1), if the normal stress, $\sigma_{\mathrm{n}}$, on the joint surface is less than the tensile strength of the joint, $\sigma_{\mathrm{n}}$ is set to 0 , which indicates a damaged joint surface. The tangential stress acts on the joint in the parallel direction, and its magnitude is controlled by the tangential stiffness coefficient, $K_{\mathrm{s}}$, with a maximum tangential stress, $\tau_{\max }$. The relationship between the tangential stress and the displacement can be divided into two conditional statements as follows:

$$
\tau_{\max }=c+\sigma_{\mathrm{n}} \tan \varphi,
$$

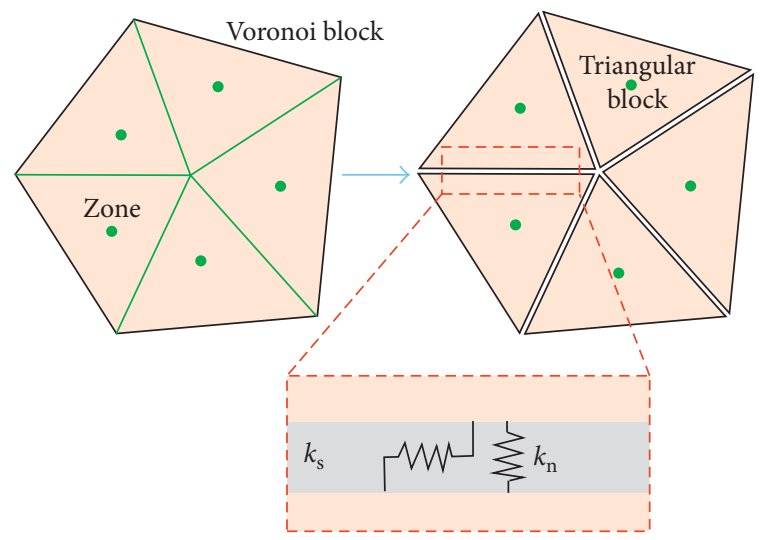

FIGURE 6: Voronoi steps of dividing blocks into triangular blocks and defining the shear and normal stiffness values between blocks.

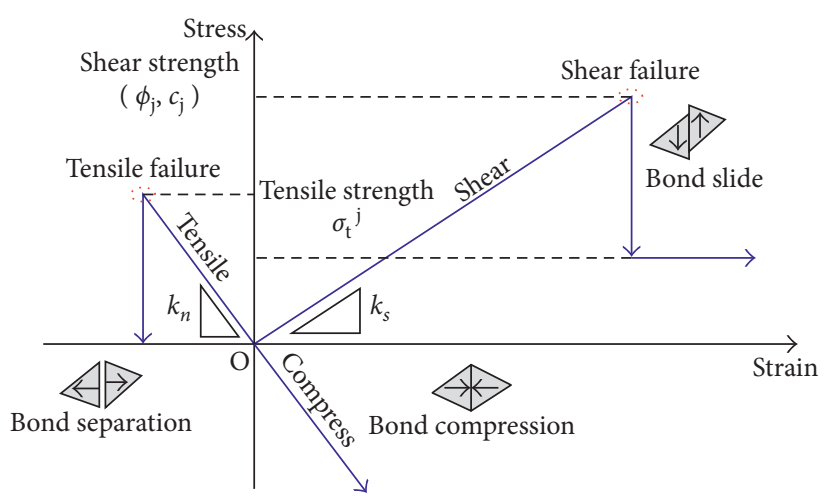

Figure 7: The constitutive contact model.

when $\left|\tau_{\mathrm{s}}\right| \leq \tau_{\max }$, then

$$
\Delta \tau_{\mathrm{s}}=K_{\mathrm{s}} \Delta u_{\mathrm{s}}^{\mathrm{e}},
$$

when $\left|\tau_{s}\right| \geq \tau_{\max }$, then

$$
\Delta \tau_{\mathrm{s}}=\operatorname{sign}\left(\Delta u_{\mathrm{s}}\right) \tau_{\max }
$$

where $\Delta u_{\mathrm{s}}^{\mathrm{e}}$ is the elastic tangential displacement increment and $\Delta u_{\mathrm{s}}$ is the total tangential displacement increment. 
Table 4: Properties of the intact rock mass.

\begin{tabular}{|c|c|c|c|c|c|}
\hline Lithology & RQD & $E_{\mathrm{r}}(\mathrm{GPa})$ & $E_{\mathrm{m}}(\mathrm{GPa})$ & $\sigma_{\mathrm{r}}(\mathrm{MPa})$ & $\sigma_{\mathrm{m}}(\mathrm{MPa})$ \\
\hline Mudstone 1 & 60 & 4.6 & 0.8 & 15.7 & 5.0 \\
\hline Gritstone 1 & 56 & 10.0 & 1.4 & 38.1 & 10.8 \\
\hline Mudstone 2 & 35 & 4.6 & 0.3 & 19.1 & 3.1 \\
\hline Number 9 coal & 31 & 3.2 & 0.2 & 11.7 & 1.7 \\
\hline Mudstone 3 & 41 & 4.6 & 0.5 & 19.1 & 3.6 \\
\hline Medium-fine sandstone & 70 & 13.0 & 3.2 & 36.3 & 15.0 \\
\hline Gritstone 2 & 76 & 9.0 & 2.9 & 36.6 & 17.8 \\
\hline Mudstone 4 & 80 & 4.6 & 1.7 & 17.4 & 9.4 \\
\hline Number 11 coal & 82 & 3.2 & 1.3 & 11.7 & 6.7 \\
\hline
\end{tabular}

In UDEC simulation, rock material is regarded as a large number of deformable microblocks, bound together by contacts. The average block size is selected to provide the numerical model with a sufficient number of blocks to obtain stable and repeatable results. The mechanical properties of different rocks are defined by indicating the contact parameters of single blocks and the contact parameters between blocks. The deformation characteristics of each block are represented by the bulk modulus, $K$, and the shear modulus, $G$. The deformation at block-block contacts are characterised by the contact normal stiffness, $K_{\mathrm{n}}$, and the tangential stiffness, $K_{\mathrm{s}}$. The contact strength is defined by the contact friction angle, $j_{\mathrm{k}}$, the cohesion, $C_{\mathrm{j}}$, and the tensile strength, $j_{\mathrm{t}}$. The Voronoi block is shown in Figure 6, and the constitutive contact model is shown in Figure 7.

4.2. Calibration of Microparameters. Using rock mechanic tests, we measured the physical and mechanical parameters of the coal in the number 39107 auxiliary transportation roadway, as shown in Table 1 . However, the mechanical parameters from the laboratory are based on the intact rock test and are different from the physical and mechanical parameters of rock mass fractured in the field. Zhang and Einstein [17] found a relationship between laboratory and field measurements that depends on the rock quality index (RQD) and the deformation modulus:

$$
\frac{E_{\mathrm{m}}}{E_{\mathrm{r}}}=10^{0.0186 \mathrm{RQD}}-1.91,
$$

where $E_{\mathrm{r}}$ and $E_{\mathrm{m}}$ express the deformation modulus of rock and rock mass, respectively. Singh and Seshagiri [18] used an empirical method to obtain a relationship between the ratio of rock to rock uniaxial compressive strength and the deformation modulus:

$$
\frac{\sigma_{\mathrm{cm}}}{\sigma_{\mathrm{c}}}=\left(\frac{E_{\mathrm{m}}}{E_{\mathrm{r}}}\right)^{n},
$$

where $\sigma_{\mathrm{c}}$ and $\sigma_{\mathrm{cm}}$ express the uniaxial compressive strength of rock and rock mass, respectively, and $n$ is 0.72 . Using (5) and (6) and the rock parameters from Table 1, we obtain the physical and mechanical parameters of the different rock mass, as shown in Table 2. The value of RQD is calculated using the borehole video of number 39107 auxiliary transport roadway in the Pingshuo coal mine and the uniaxial tensile strength, assuming a $10 \%$ rock compressive strength $\left(\sigma_{\mathrm{c}}\right)$.
According to the physical and mechanical characteristics of the rock mass, the parameters were calculated and are shown in Table 4.

Required inputs include the microparameters of the block and the contact, which do not directly depend on the physical and mechanical characteristics of rock mass. Therefore, this study uses a uniaxial compression simulation to calibrate the microparameters through UDEC triangle blocks. The simulation and the specimen failure mode are shown in Figure 8.

The values of $K$ and $G$ used in the UDEC model can be calculated by incorporating the elastic modulus, $E$ (obtained from the uniaxial compression experiment), into the following formulas:

$$
\begin{aligned}
& K=\frac{E}{3(1-2 \mu)}, \\
& G=\frac{E}{2(1+\mu)},
\end{aligned}
$$

As the programme time step depends on the magnitude of the joint stiffness, an incorrect or inappropriate value for this parameter will affect convergence rate calculations.

Joint stiffness of the contact surface is calculated as follows $[19,20]$ :

$$
\begin{aligned}
& k_{\mathrm{n}}=10\left[\frac{K+(3 / 4) G}{\Delta z_{\text {min }}}\right], \\
& k_{\mathrm{s}}=0.4 k_{\mathrm{n}},
\end{aligned}
$$

where $\Delta z_{\min }$ is the minimum width of the block node from the adjacent contact surface.

The cohesive force, internal friction angle, and tensile strength of the contact surface are the microparameters in this calculation. For these parameters, we first assume initial values and then compare these to the simulated results. We also compare the macroparameters with the results of the simulation. Finally, we modify the initial parameters according to the results of these comparisons.

We continue to simulate the microparameters (required in the final UDEC simulation) until the results agree with the rock mechanic parameters. The simulations of the stressstrain curves in the rock strata are shown in Figure 8. The calibrated parameters are shown in Table 5. 

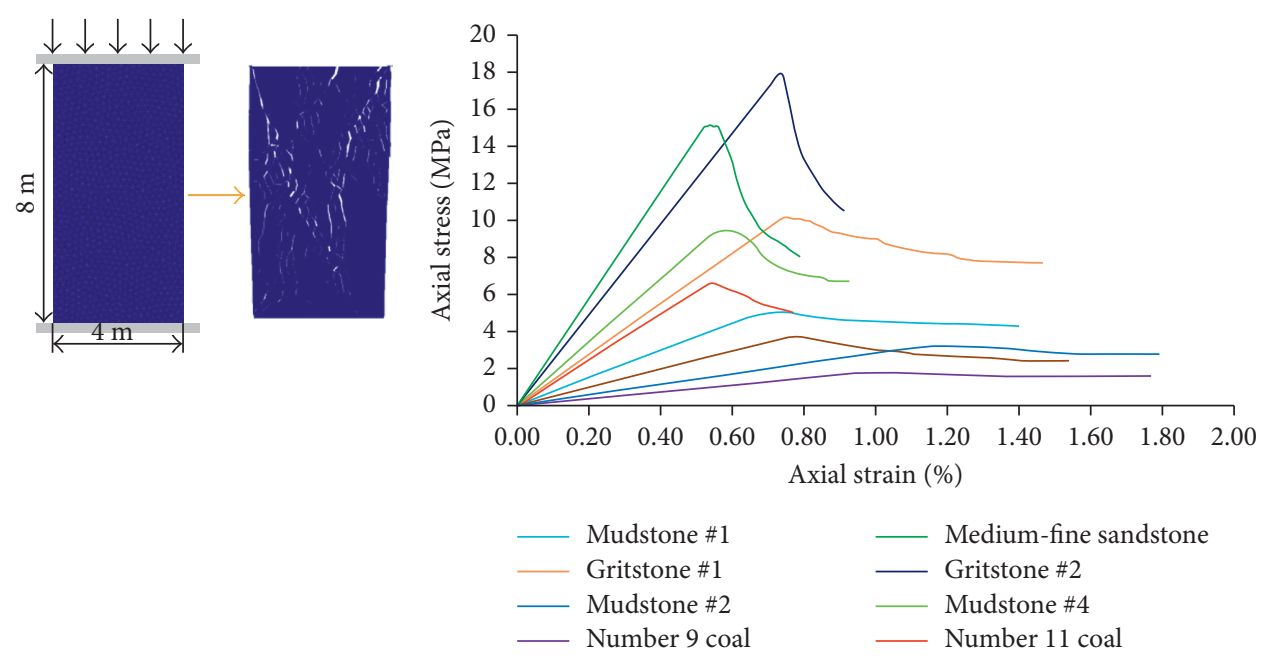

(a)

(b)

FIGURE 8: Uniaxial compression simulation tests: (a) schematic diagram and failure mode and (b) simulated stress and strain curves.

TABLE 5: Calibrated microparameters.

\begin{tabular}{|c|c|c|c|c|c|c|c|c|}
\hline \multirow{2}{*}{ Lithology } & \multicolumn{3}{|c|}{ Matrix properties } & \multicolumn{5}{|c|}{ Contact properties } \\
\hline & Density $\left(\mathrm{kg} / \mathrm{m}^{3}\right)$ & $K(\mathrm{GPa})$ & $G(\mathrm{GPa})$ & $k_{\mathrm{n}}(\mathrm{GPa} / \mathrm{m})$ & $k_{\mathrm{s}}(\mathrm{GPa} / \mathrm{m})$ & $C_{\mathrm{j}}(\mathrm{MPa})$ & $\Phi_{\mathrm{j}}\left(\right.$ peak/residual, $\left.{ }^{\circ}\right)$ & $\sigma_{\mathrm{t}}^{\mathrm{j}}(\mathrm{MPa})$ \\
\hline Mudstone \#1 & 2370 & 0.53 & 0.32 & 54.69 & 21.88 & 1.85 & $35 / 30$ & 0.30 \\
\hline Gritstone \#1 & 2652 & 0.86 & 0.57 & 91.30 & 36.52 & 4.20 & $37 / 33$ & 0.80 \\
\hline Mudstone \#2 & 2346 & 0.23 & 0.12 & 22.29 & 8.92 & 1.15 & $35 / 30$ & 0.20 \\
\hline Number 9 coal & 1498 & 0.13 & 0.08 & 13.67 & 5.47 & 0.70 & $30 / 24$ & 0.10 \\
\hline Mudstone \#3 & 2346 & 0.30 & 0.21 & 31.92 & 12.77 & 1.45 & $35 / 30$ & 0.28 \\
\hline Medium-fine sandstone & 2641 & 1.98 & 1.30 & 208.69 & 83.47 & 6.30 & $30 / 24$ & 1.00 \\
\hline Gritstone \#2 & 2450 & 1.93 & 1.16 & 113.29 & 45.32 & 6.90 & $37 / 33$ & 1.20 \\
\hline Mudstone \#4 & 2332 & 1.36 & 0.70 & 133.73 & 53.49 & 3.60 & $35 / 30$ & 0.50 \\
\hline Number 11 coal & 1498 & 0.98 & 0.51 & 96.58 & 38.63 & 2.70 & $30 / 24$ & 0.40 \\
\hline
\end{tabular}

4.3. Model Setup. Combining the characteristics of the UDEC triangle block numerical model above, this paper establishes a model for the number 39107 roadway.

In order to improve calculation efficiency, this paper uses the triangular block model for the roadway to simulate rock strata in other areas. In some locations, the rectangular block model is used to simulate the rock strata. In the area surrounding the coal seam, each random triangular block has a length of $0.2 \mathrm{~m}$ and an area of $0.017 \mathrm{~m}^{2}$. The sizes of the triangular blocks in the mudstone and medium sandstone units are $0.3 \mathrm{~m}$ and $0.45 \mathrm{~m}$, respectively. Thus, as this model incorporates realistic field conditions, it effectively simulates the failure processes in the soft, weak, efflorescent-oxidised rocks surrounding the roadway. In order to avoid a sudden size increase of a model block, the dimensions of the rectangular block outside of the triangular block gradually increase. The modelled area is $60 \mathrm{~m} \times 51.6 \mathrm{~m}$ and includes a total of 9014 blocks. The lateral boundary of the model is fixed in the horizontal and vertical directions. In accordance with the ground stress test results, the vertical stress is $5.6 \mathrm{MPa}$ to simulate the weight of overlying strata and the horizontal (tectonic) stress is 7.2 MPa. The numerical model of the number 39107 roadway is shown in Figure 9.

First, the model is run to equilibrium under the boundary stress conditions. Then the model eliminates a block to simulate the excavation of the roadway. As the roadway is progressively excavated by a roadway machine, there are complex temporal and spatial effects. UDEC is a $2 \mathrm{D}$ numerical simulation and to achieve $3 \mathrm{D}$ conditions, we apply a virtual force, $F$, on the tunnel walls. By gradually releasing the support reaction force, we can control the final convergence of tunnel wall displacement (Figure 10) [21].

Therefore, in order to realistically simulate the decreasing stress on the surrounding rock during the roadway excavation, we use UDEC embedded with a FISH function to divide the rock stress into 10 grades of attenuation, each showing a $10 \%$ decrease from the previous grade. The model runs to the programmed balancing force and then progresses to the next stress attenuation level. 


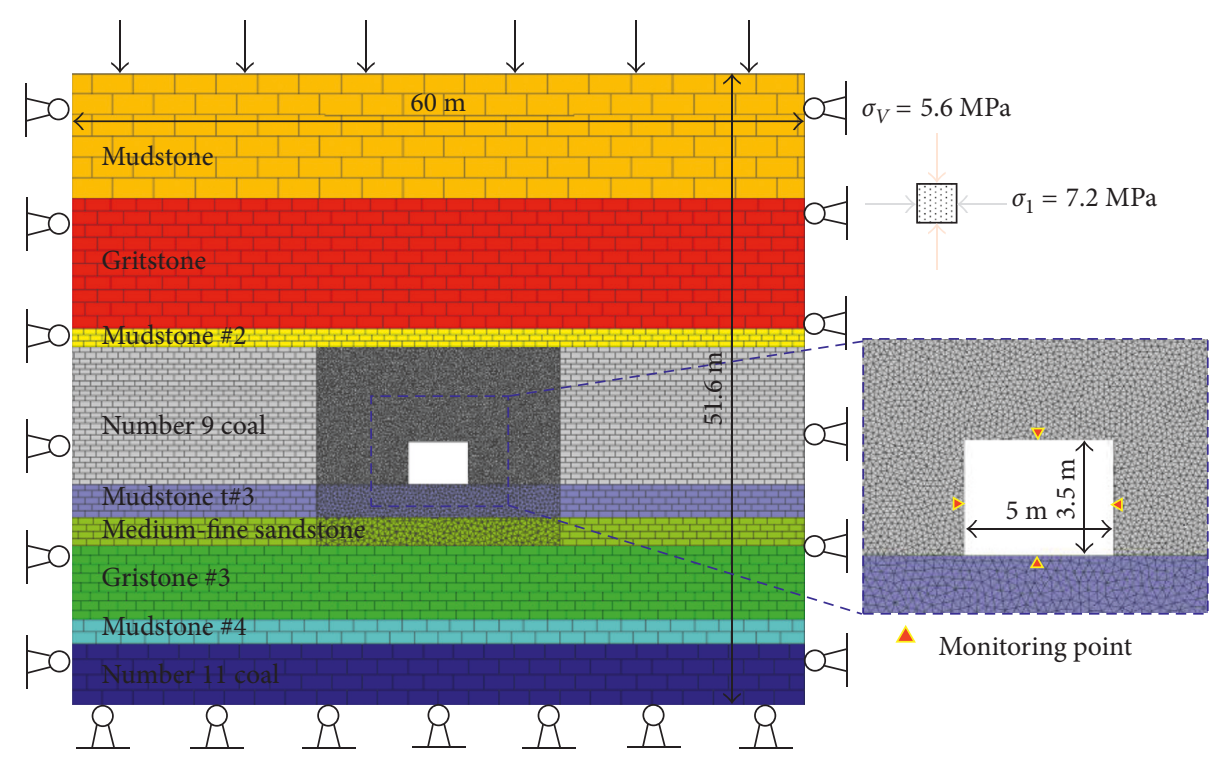

FIGURE 9: Numerical model of the number 39107 roadway.

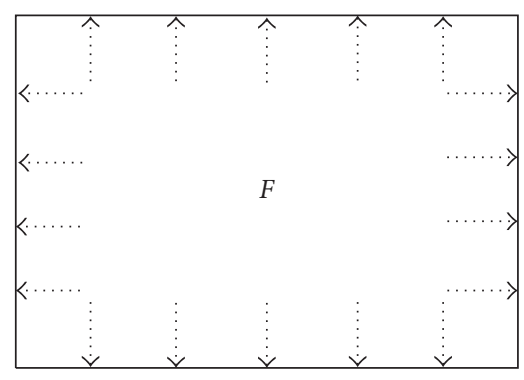

(a)

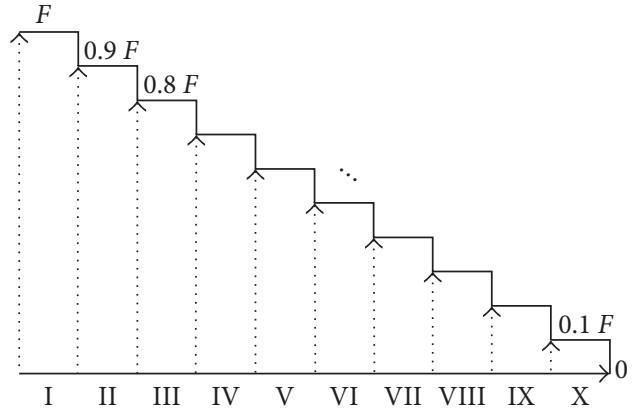

(b)

FIgURE 10: The model diagram: (a) virtual supporting force and (b) step of unloading path.

\subsection{Simulation of Excavation in the Absence of Support}

4.4.1. Analysis of Roadway Rock Displacement. After the excavation of the number 39107 roadway, four displacement monitoring points were established on the roof, floor, and the middle of the two side ribs of the roadway. The monitoring results are shown in Figures 11-13.

After roadway excavation, the displacement measured at the monitoring points continuously increases. In the first nine stages of the model, the deformation rate of the rock is stable. However, after unloading, the deformation rate greatly increases. The deformation rate and total deformation of the two groups are similar, but the amount of floor heave is lower. The deformation growth rate of roof subsidence is greater than that of the two side ribs and the floor.

Roof subsidence on the right-hand side of the roof shows the largest displacement vector of $1100 \mathrm{~mm}$. The two groups have a similar amount of extrusion, and the maximum amount of floor heaver displacement is approximately $320 \mathrm{~mm}$. From the direction of the displacement vector in the surrounding rock in Figure 12, shear failure occurs on the roadway roof, while tensile failure occurs in the floor.

The failure mode in Figure 13 shows that there is a large amount of broken rock mass observed in the roof rock and gravity will cause additional rock to fall. The two groups are the triangle and the sliding failure areas. The bottom of the surrounding rock is crowded in the wrong movement, resulting in the floor heave.

4.4.2. Stress Analysis. After excavation, the surrounding rock stress is released. At the initial stage, the stress concentration zone appears in the worst position at the edge of the stress state. The maximum principal stress is $20 \mathrm{MPa}$, and the stress concentration factor is approximately 3.0, resulting in the extrusion of the surrounding rock.

With the release of stress, both the roadway surface pressure and the surrounding rock strength decrease. When the stress increases and exceeds the surrounding rock strength, the surrounding rock is destroyed. In this scenario, bearing structure stress is transferred deeper into the 


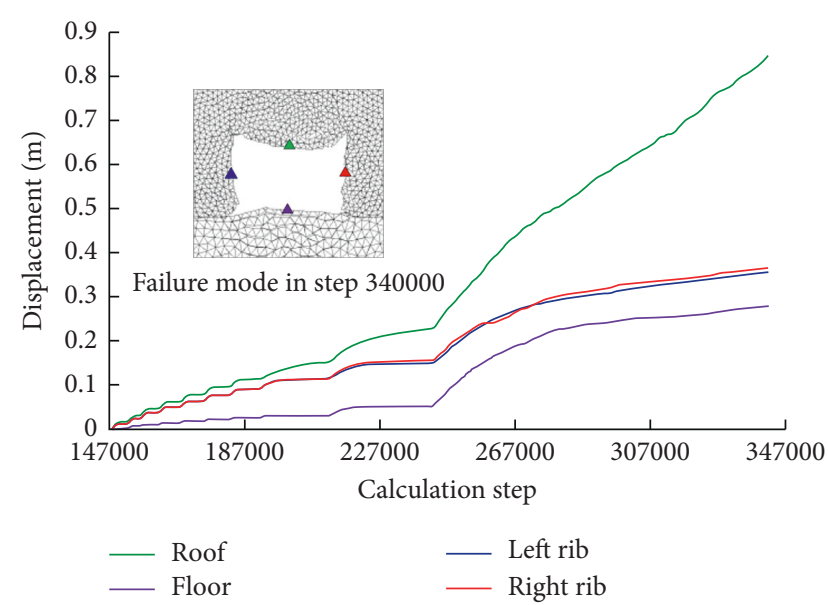

FIGURE 11: Calculated displacement at various time steps.

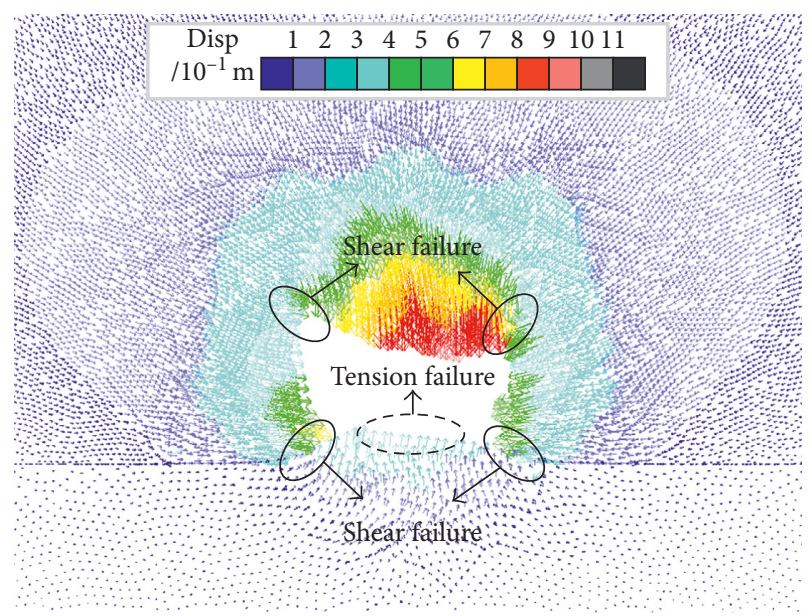

FIGURE 12: Displacement vector graph in the absence of support.

surrounding rock and a large area of stress relaxation appears in the shallow surrounding rock. According to the minimum principal stress, the loss of roadway support moves rock onto the roadway, resulting in mutual extrusion.

Furthermore, the maximum and minor stresses on the surface of the surrounding rock increase causing the surrounding rock stress state to rapidly deteriorate and deform (Figure 14).

4.4.3. Crack Propagation in the Surrounding Rock. After roadway excavation, the stress in the surrounding rock gradually decreases and concentrates in the roadway corners. Thus, the four corners of the roadway achieve the first fracture failures due to high compressive stresses.

As stress continues to release into the VIII stage, shear failure occurs due to gravitational and horizontal stresses on the middle roof section of the tunnel. A large number of roof cracks appear and extend from the two corners of the roadway to form an arch-like fracture surface. When the stress is released in the IX stage, there is a considerable overburden gravity transfer from the roof to these two crack zones due to roof damage. Under the vertical and horizontal

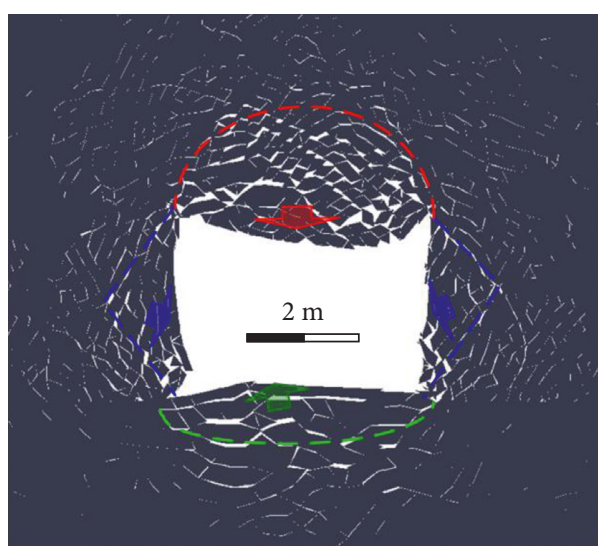

FIGURE 13: Surrounding rock damage.

stresses, these two crack zones extend along the roadway and eventually intersect. While the roof cracks develop, stress cracks expand and penetrate to the middle section of the floor. When the stress is released, roadway width increases due to the propagation of the two crack zones and a negative feedback loop [22] that leads to cracks penetrating deeper into the surrounding rock (Figure 15).

4.5. Numerical Simulation of the Support Scheme. Adding supporting measures to the deformed area in the model reduced the displacement of the surrounding rock. The properties of the support elements used in UDEC are presented in Table 6. Additionally, the displacement distribution was more uniform, and there were no obvious block collapses or slips.

As shown in Figure 16, the deformation compatibility is acceptable, and the stability of the surrounding rock is controlled. In order to assess the changes in surrounding rock deformation, four measuring lines were arranged on the roof, two side ribs, and the floor during simulation. The vertical floor and roof displacements along with the horizontal displacement of the right-hand side were extracted both before and after the added support. Results showed that roof deformation and side deformation were significantly reduced, as shown in Figure 17. Although significant deformation occurred, it was within the control range. Compared with the original roadway without support, roof subsidence decreased by $52 \%$ to $420 \mathrm{~mm}$. In addition, the displacement of each side decreased by $44 \%$ to approximately $250 \mathrm{~mm}$, while the floor heave displacement decreased by $22 \%$.

The added support results in no change in the distribution of the main stresses. According to the principal stress analysis, the added support reduces the stress relaxation zone on the roof and two side ribs and improves the stress state of the surrounding rock. However, without added support, horizontal pressure on the roadway floor results in a high tensile stress and the occurrence of a heave phenomenon (Figure 18).

Figure 19 shows the comparison of crack distribution characteristics, with the blue line indicating the dimensions 


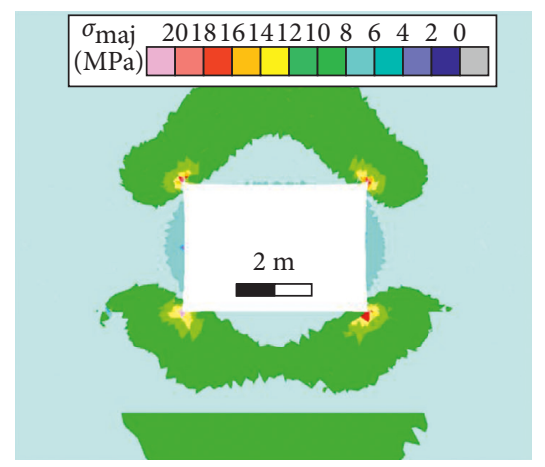

Stage VI

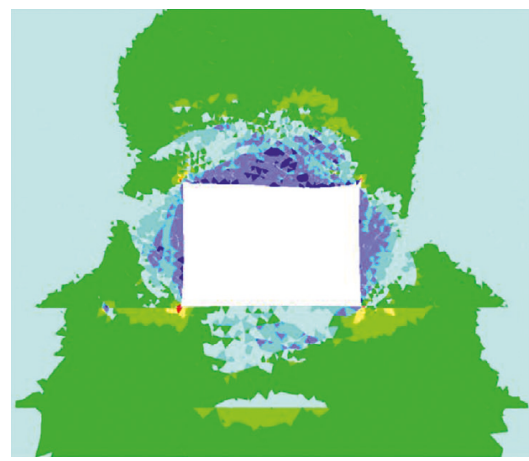

Stage IX

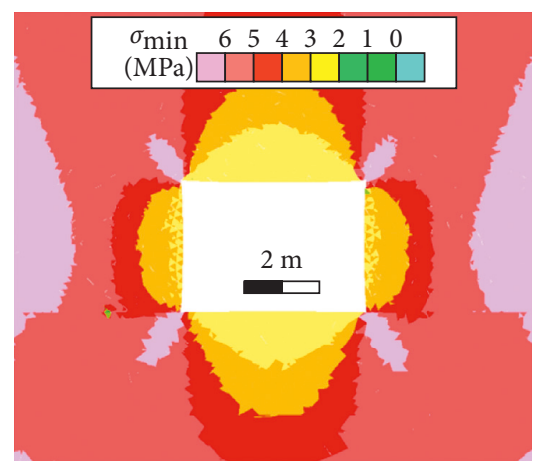

Stage VI

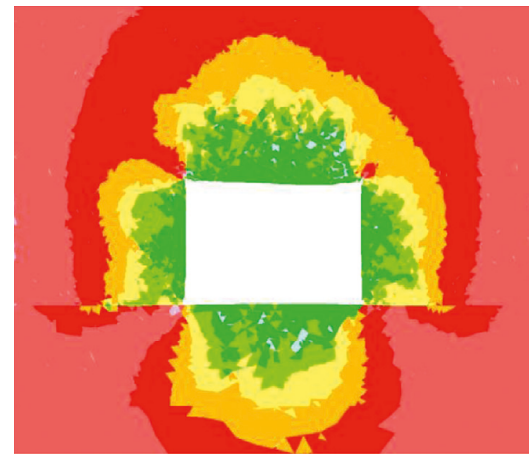

Stage IX

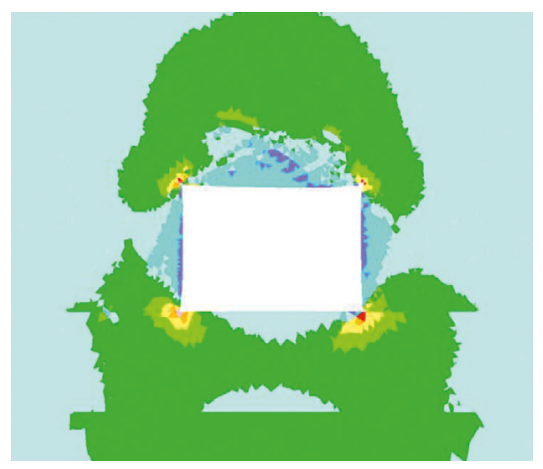

Stage VIII

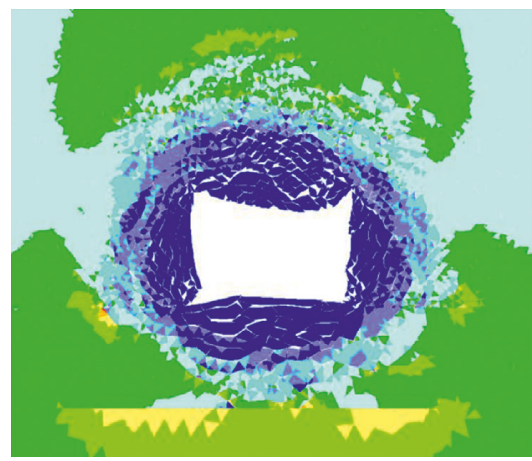

Stage X

(a)

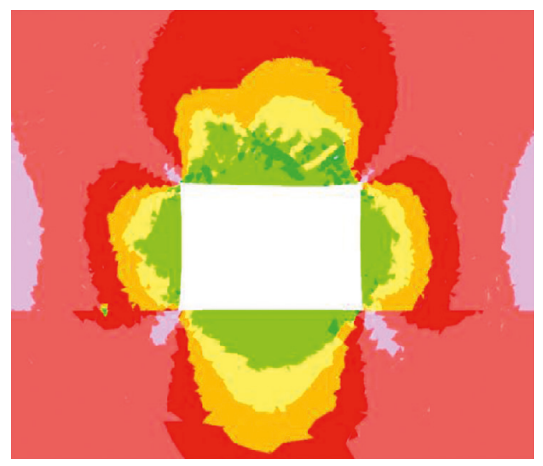

Stage VIII

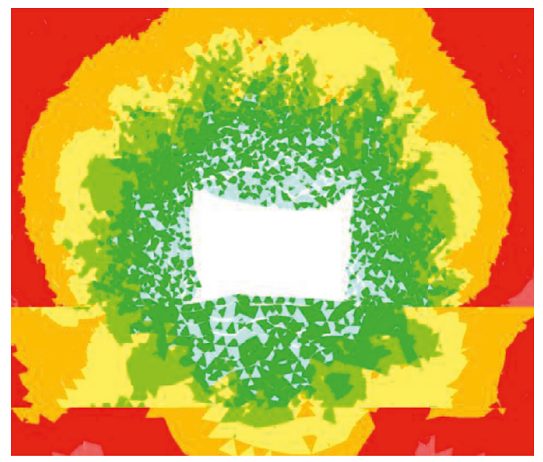

Stage X

(b)

FIGURE 14: Stress evolution diagram: (a) the maximum principal stress distribution and (b) the minor principal stress distribution. 

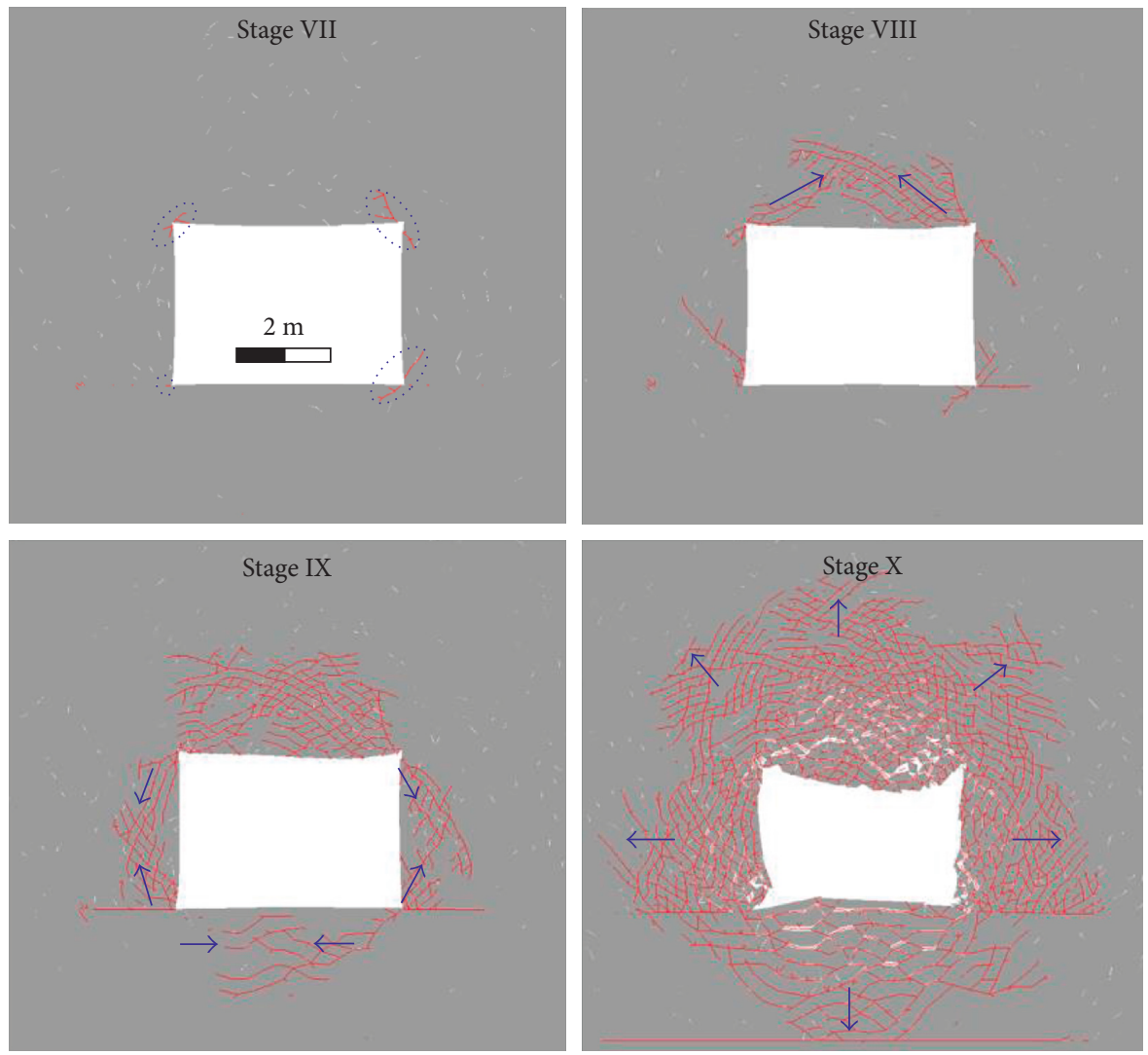

FIgURE 15: Process of crack evolution.

Table 6: Properties of the support elements.

\begin{tabular}{lcccccc}
\hline Properties & $\begin{array}{c}\text { Elastic } \\
\text { moduli }(\mathrm{GPa})\end{array}$ & $\begin{array}{c}\text { Tensile yield } \\
\text { strength }(\mathrm{kN})\end{array}$ & $\begin{array}{c}\text { Stiffness of grout } \\
(\mathrm{N} / \mathrm{m} / \mathrm{m})\end{array}$ & $\begin{array}{c}\text { Bond strength of } \\
\text { grout }(\mathrm{N} / \mathrm{m})\end{array}$ & $\begin{array}{c}\text { Interface normal } \\
\text { stiffness }(\mathrm{GPa} / \mathrm{m})\end{array}$ & $\begin{array}{c}\text { Interface shear } \\
\text { stiffness }(\mathrm{GPa} / \mathrm{m})\end{array}$ \\
\hline Bolt & 200 & 200 & $2 e 9$ & $4 e 5$ & - & - \\
Cable & 200 & 390 & $2 e 9$ & $4 e 5$ & - & - \\
Steel strip & 200 & 500 & - & - & 15 & 15 \\
\hline
\end{tabular}

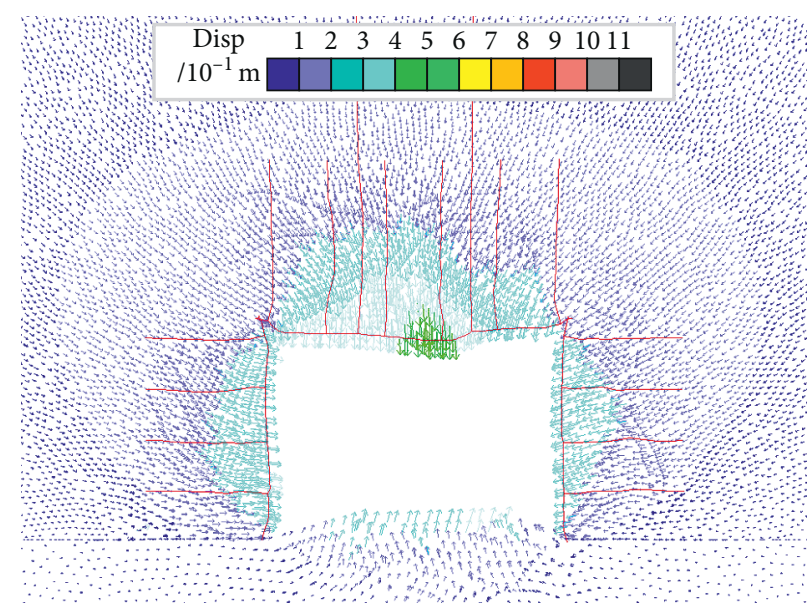

FIGURE 16: Displacement vector of the surrounding rock after added support. 


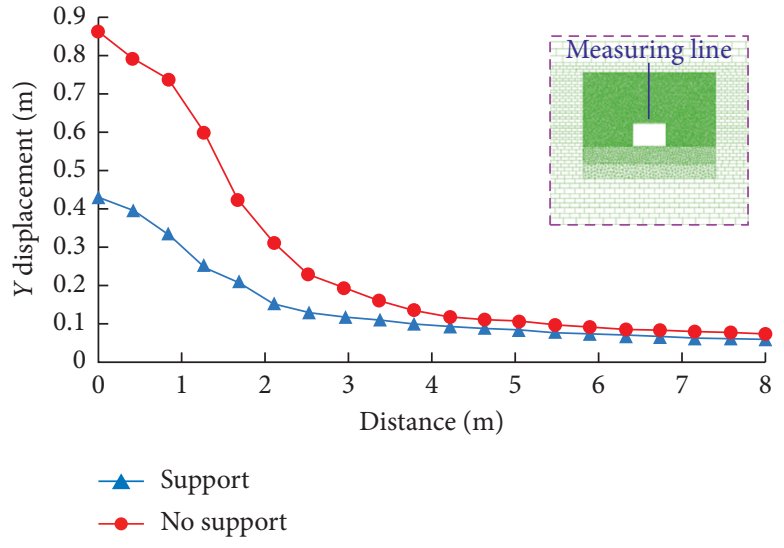

(a)

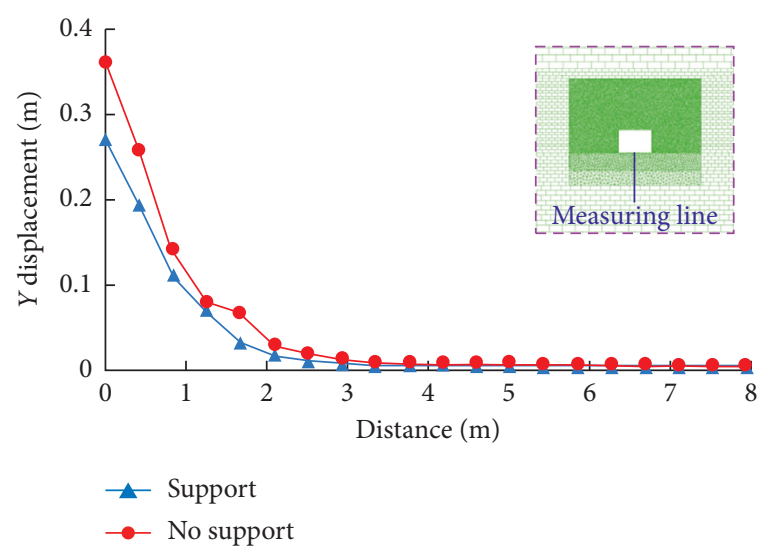

(b)

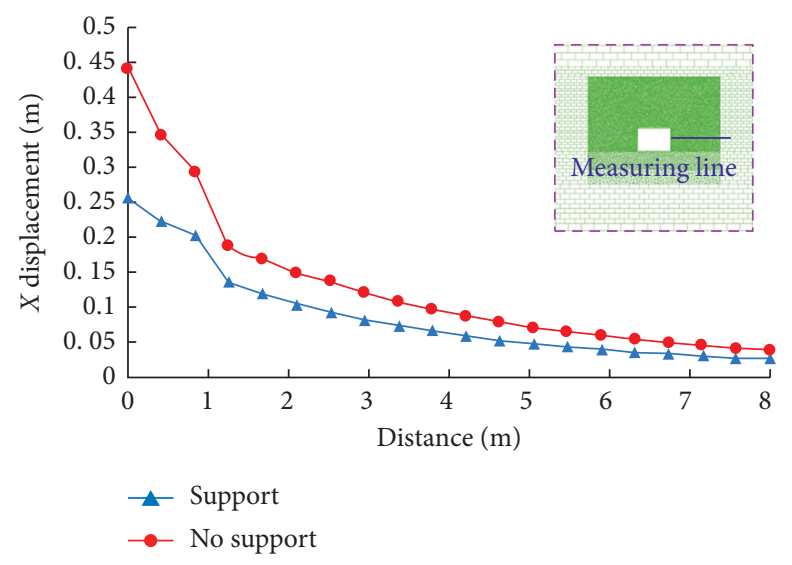

(c)

FIGURE 17: Displacement control of the surrounding rock: (a) vertical roof displacement, (b) vertical floor displacement, and (c) horizontal displacement of the right rib.

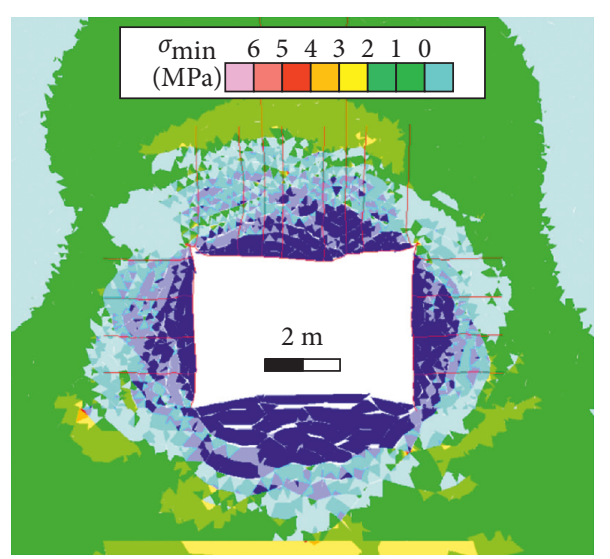

(a)

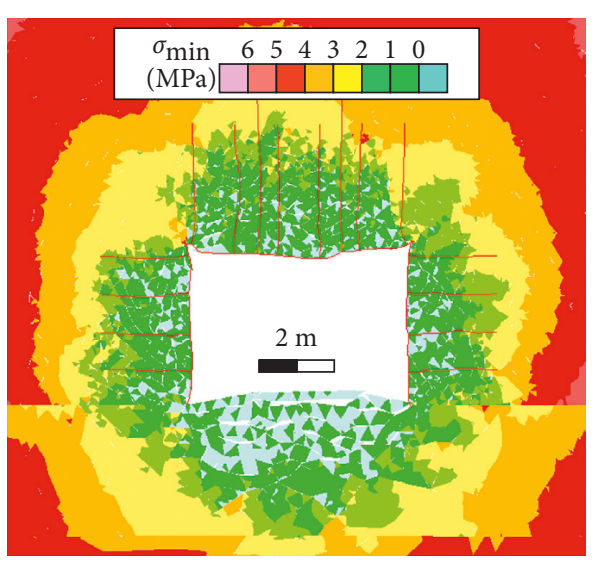

(b)

FIGURE 18: Stress distribution after added support: (a) the maximum principal stress distribution and (b) the minor principal stress distribution.

of the crack in the absence of support. This comparison shows that roof crack propagation depth is greatly reduced by the added support. This is particularly true in the upper corner cracks, indicating that the roof and the two side ribs maintain their stability. However, the degree of fracturing in the floor does not show significant improvement with added support.

In Figure 20, the red represents the axial force of the anchor and anchor cable, and the green represents the shear stress of the steel strip. The surrounding rock is affected by 


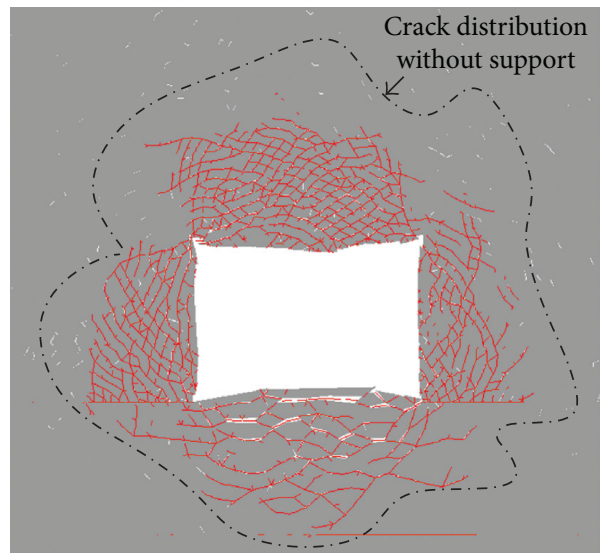

FIgURE 19: Comparison of crack distribution characteristics.
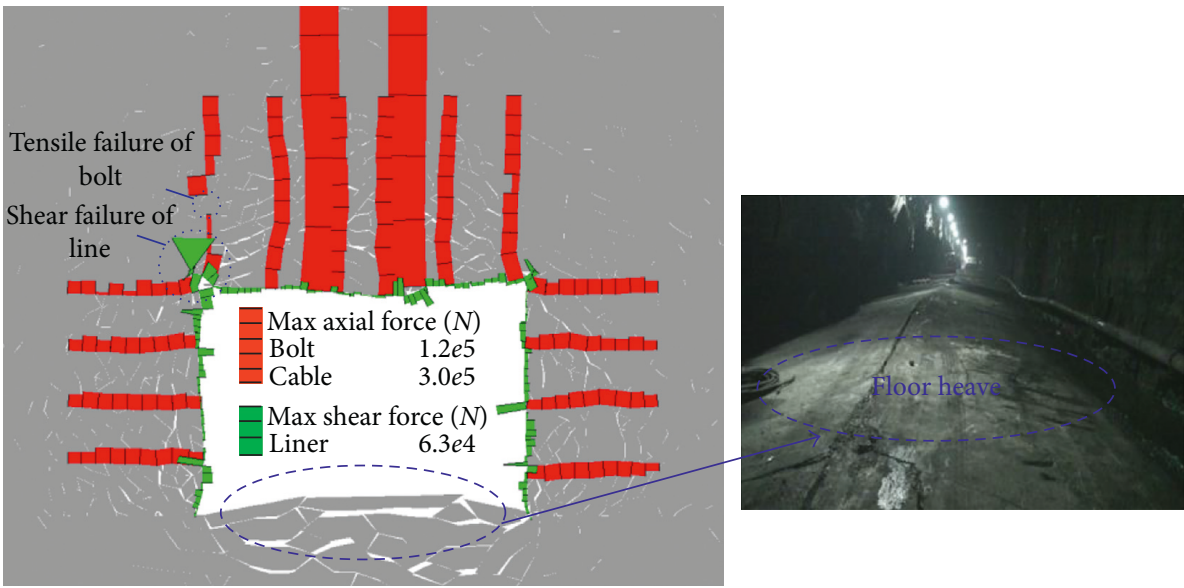

FiguRE 20: Supporting body stress state and floor heave simulation results compared to field tests.

roof subsidence and the influence of the two groups. There is a large extrusion deformation failure, resulting in the left corner of the steel strip shear failure that occurs near the corner of the top bolt pull failure. Thus, the stress state of the surrounding rock is not conducive to stability, and measures should be taken to improve the support scheme. In the simulation, floor heave also occurs and is consistent with field observations (Figure 20).

\section{Conclusion}

The deformation mechanisms of fractured rock in an efflorescent oxidation zone were investigated using the DEM. In situ stress measurements and RQD data were collected on-site. To simulate the broken, loose features of the fractured surrounding rock, a custom FISH function was developed to divide the Voronoi blocks into several constituent triangle-shaped blocks in UDEC. The RQD data were used to estimate the properties of intact rock, and UDEC was used to calibrate the microparameters of various strata. The main findings of this study are summarised as follows:

(1) The FISH function was written to separate the rock stress into 10 decaying levels, and the stress during roadway excavation was simulated using the appropriate block sizes. Additionally, the simulated rock mass had a high degree of weathering and low strength and poor stability to reflect field observations.

(2) Detailed numerical modelling was used to evaluate roadway stability and deformation under different support designs. The deformation and failure of the roadway rocks was successfully captured by applying a progressive step reduction in the boundary forces during the model runs.

(3) The simulation showed significant deformation of the surrounding rock after roadway excavation, including roof collapses, side spallation, and floor heave. Adoption of the original support scheme improved the stress state of the surrounding rock and decreased the total amount of deformation. Despite the addition of supports, floor heave was still a significant issue.

\section{Conflicts of Interest}

The authors declare that there are no conflicts of interest regarding the publication of this paper. 


\section{Acknowledgments}

This research work was financially supported by the National Key Research and Development Plan (Grant no. 2017YFC0603001), the Science and Technology Research Foundation of Universities and Colleges in Hebei Province of China (Grant nos. Z2017045 and 2018102001358), the Science and Technology Plan Foundation of Hebei Province of China (Grant no. 16274108), the Fundamental Research Funding for the Central Universities of China (Grant no. 3142015087), and the National Natural Science Foundation of China (Grant nos. 51574224, 51404251, and 51774012).

\section{References}

[1] B. S. Yang and W. J. Duan, "Study on the law of coal layer safe extraction in efflorescent oxygenized belts," Journal of China Coal Society, vol. 28, no. 6, pp. 608-612, 2003.

[2] B. S. Yang, Y. F. Kong, and Q. Y. Yu, "Research of coal layer safe extraction in efflorescent oxygenized belts," Journal of China University of Mining and Technology, vol. 33, no. 1, pp. 50-54, 2004.

[3] Y. Q. Xuan, Q. Wu, and B. S. Yang, "Weathered damage attributes of rock and law of reducing protection coal column," Journal of China University of Mining and Technology, vol. 33, no. 6, pp. 678-681, 2004.

[4] Y. Q. Xuan, Q. Wu, and B. S. Yang, "Study on the weathered damage attributes of rock and the law of reduction for coal column protection," Chinese Journal of Rock Mechanics and Engineering, vol. 24, no. 11, pp. 1911-1916, 2005.

[5] D. Tian, Q. F. Zhao, and G. N. Shao, "Research on strata behaviors and variation characteristics of overburden strata of fully mechanized top coal caving in mining efflorescent oxygenized zone," Journal of Mining \& Safety Engineering, vol. 32, no. 5, pp. 808-813, 2015.

[6] Q. Meng, L. Han, and Y. Chen, "Influence of dynamic pressure on deep underground soft rock roadway support and its application," International Journal of Mining Science and Technology, vol. 26, no. 5, pp. 903-912, 2016.

[7] M. C. He, Y. Yuan, X. L. Wang, Z. Q. Wu, C. Liu, and Y. L. Jiang, "Control technology for large deformation of mesozoic compound soft rock in Xinjiang and its application," Chinese Journal of Rock Mechanics and Engineering, vol. 32, no. 3, pp. 433-441, 2013.

[8] L. G. Wang, Y. L. Lu, Y. G. Huang, and H. Y. Sun, "Deep-shallow coupled bolt-grouting support technology for soft rock roadway in deep mine," Journal of China University of Mining and Technology, vol. 45, no. 1, pp. 11-18, 2016.

[9] H. P. Kang, J. Lin, and M. J. Fan, "Investigation on support pattern of a coal mine roadway within soft rocks-a case study," International Journal of Coal Geology, vol. 140, pp. 31-40, 2015.

[10] B. T. Shen, "Coal mine roadway stability in soft rock: a case study," Rock Mechanics and Rock Engineering, vol. 47, no. 6, pp. 2225-2238, 2014.

[11] F. Q. Gao, "Simulation of failure mechanics around underground coal mine openings using discrete element modelling," Ph.D. thesis, Simon Fraser University, Burnaby, BC, Canada, 2013.

[12] P. A. Cundall, "A computer model for simulating progressive, large-scale movements in blocky rock systems," Procrit Symptom Rock Fracture, vol. 1, pp. 1-8, 1971.
[13] L. Jing and O. Stephansson, Fundamentals of Discrete Element Methods for Rock Engineering, Theory and Application, Elsevier, Amsterdam, Netherlands, 2007.

[14] P. A. Cundall and R. D. Hart, "Numerical modelling of discontinue," Engineering Computations, vol. 9, no. 2, pp. 101-113, 1992.

[15] T. Kazerani and J. Zhao, "A microstructure-based model to characterize micromechanical parameters controlling compressive and tensile failure in crystallized rock," Rock Mechanics and Rock Engineering, vol. 47, no. 2, pp. 435-452, 2014.

[16] M. Chen, S. Yang, Y. Zhang, and C. Zang, "Analysis of the failure mechanism and support technology for the Dongtan deep coal roadway," Geomechanics and Engineering, vol. 11, no. 3, pp. 401-420, 2016.

[17] L. Zhang and H. H. Einstein, "Using RQD to estimate the deformation moduli of rock masses," International Journal of Rock Mechanics and Mining Sciences, vol. 41, no. 2, pp. 337-341, 2004.

[18] M. Singh and R. K. Seshagiri, "Empirical methods to estimate the strength of jointed rock masses," Geomechanics and Engineering, vol. 77, no. 1-2, pp. 127-137, 2005.

[19] ITASCA, UDEC, Version 4.0, Itasca Consulting Group Inc., Minneapolis, MN, USA, 2004.

[20] F. Q. Gao and D. Stead, "The application of a modified Voronoi logic to brittle fracture modelling at the laboratory and field scale," International Journal of Rock Mechanics and Mining Sciences, vol. 68, pp. 1-14, 2014.

[21] L. Meyer, "Numerical modelling of ground deformation around underground development roadways, with emphasis on three-dimensional modelling of the effects of high horizontal stress," Ph.D. thesis, University of Exeter, Exeter, UK, 2002.

[22] Z. Zhou, L. Chen, Y. Zhao, T. Zhao, X. Cai, and X. Du, "Experimental and numerical investigation on the bearing and failure mechanism of multiple pillars under overburden," Rock Mechanics and Rock Engineering, vol. 50, no. 4, pp. 995-1010, 2017. 


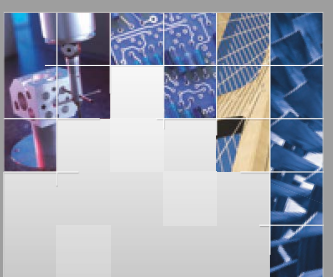

\section{Enfincering}
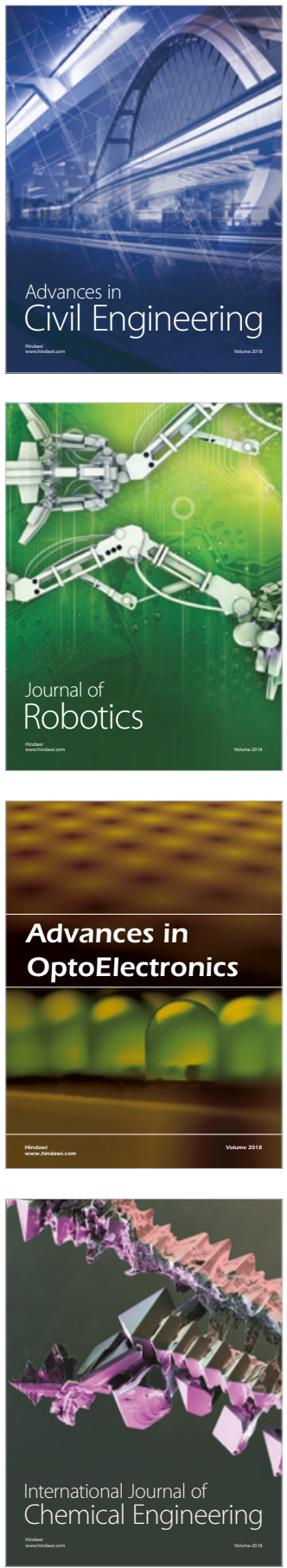

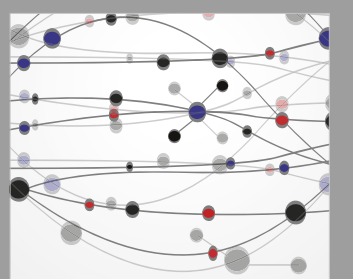

\section{Rotating \\ Machinery}

The Scientific World Journal

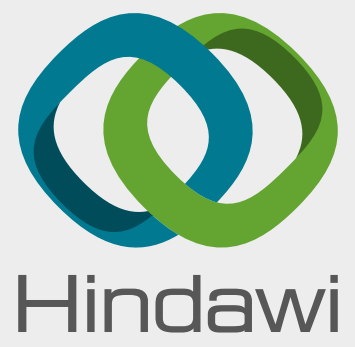

Submit your manuscripts at

www.hindawi.com
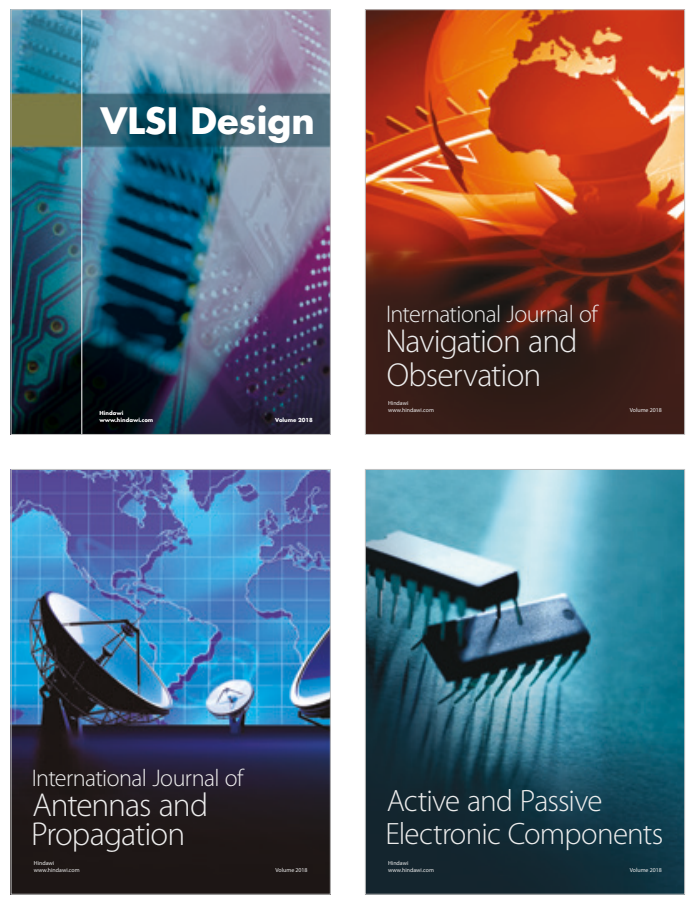
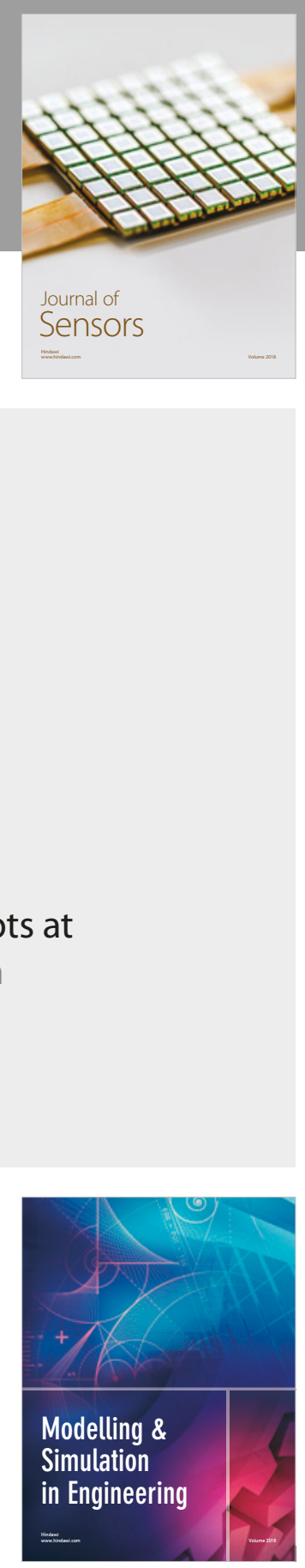

\section{Advances \\ Multimedia}
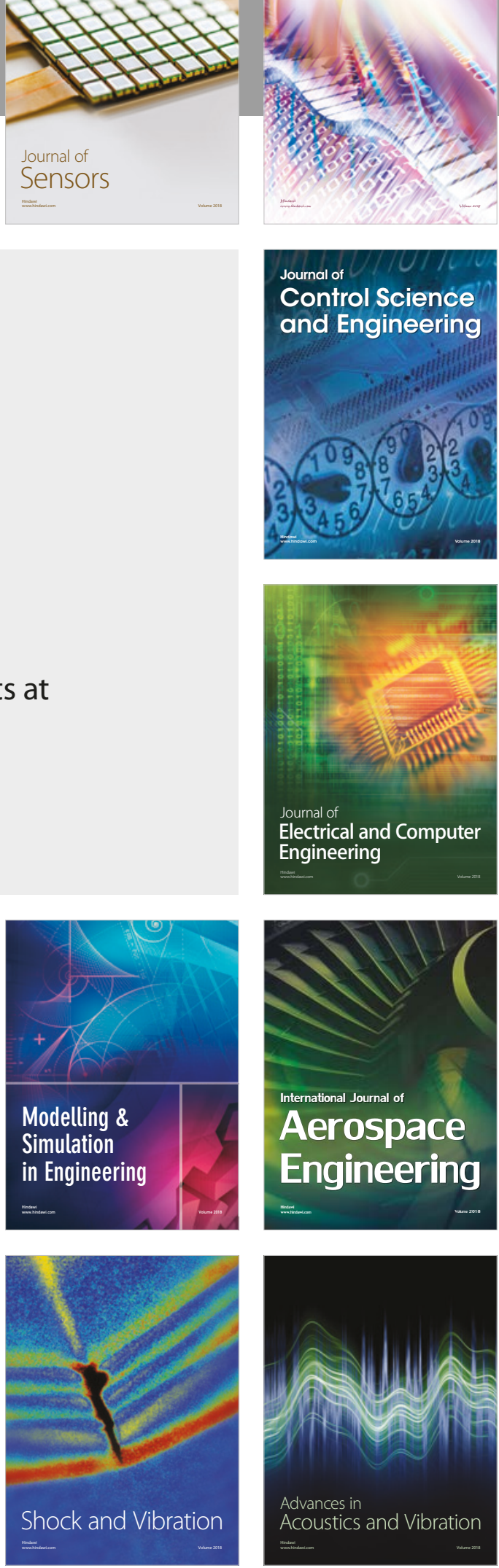